\title{
Extinction of avoidance behavior: Comparison of various flooding procedures in rats*
}

\section{MORRIE BAUM* \\ Universite de Moncton, Moncton, Nouveaux Brunswick, Canada}

Five groups of rats were given an avoidance-extinction session immediately after acquisition and flooding or a control procedure. Flooding consisted of exposing the animal to the feared situation (CS) in the absence of shock, while removing the avoidance contingency. Flooding was carried out in three different ways, the object being to compare different techniques of flooding. Two forms of flooding, reducing the intertrial interval to zero (prolonging the "CS") or response blocking (prevention), were found to be equally effective in producing the rapid cessation of avoidance responding in extinction. Both were superior to a third technique of flooding which involved removing part of the apparatus to render the avoidance response impossible during flooding. Reasons for this differential efficacy of three flooding procedures were discussed.

While avoidance responding may persist for a great many trials in extinction, extinction can be greatly accelerated by procedures which have been referred to as "flooding" or "response prevention" or "detainment." Baum (1971) has recommended the term flooding to refer to these techniques, all of which have in common that they expose the organism to the feared cues or CS underlying the behavior while removing the avoidance contingency. While flooding is undoubtedly effective in hastening avoidance extinction (e.g., Baum, 1966), there are several waus in which the technique can be applied. One method of administering flooding involves allowing the avoidance response to be made at will by the animal, but seeing to it that the CS is not terminated (e.g., Bankart, 1971; Heath, 1968; Polin, 1959; Shearman, 1970). This flooding (Type 1) has been what is conventionally referred to as flooding (initially named by Polin, 1959). In the shuttlebox, flooding-1 involves simply keeping the CS on while the $S$ is permitted to respond by hurdle jumping as frequently as it desires; in the ledge box, a one-way avoidance situation (see Baum, 1966), flooding-1 involves beginning a new trial as soon as the response is made, thus it entails reducing the intertrial interval to zero.

Another type of flooding, flooding-2, involves blocking or thwarting the avoidance response while

*This research was supported by a grant to the author from the National Research Council of Canada. The author is grateful to Robert Leclerc for his help in carrying out this study. The study was first reported at the meeting of the Psychonomic Society, St. Louis, 1972.

+Reprints may be obtained from Morrie Baum, Visitin Associate Professor, Department de Psychologie, Universite de Moncton, N.-B., Canada. exposing the organism to the feared CS or cues. This form of flooding has been conventionally referred to as response prevention (Page \& Hall, 1953) or response blocking. In the shuttlebox or one-way, Miller-type avoidance task, flooding-2 typically involves placing a barrier across the middle of the apparatus physically rendering impossible the response of crossing to the other side of the apparatus (Bersh \& Keltz, 1971; Kamano, 1968; Linton, Riccio, Rohrbaugh, \& Page, 1970; Schiff, 1971). A third type of flooding, flooding-3, involves removing a part of the avoidance apparatus and in this way making it impossible for the animal to perform the avoidance response. In the case of leverpress avoidance, the lever is simply withdrawn from the chamber while the CS is presented without shock (Reid, Taylor, \& Rassel, 1971). In the ledge box of Baum (1966), flooding-3 entails removing the safety ledge from the apparatus so that it is impossible for the animal to climb on it.

Since there are three distinctly different flooding procedures, the question arises as to which is the most effective in hastening avoidance extinction. Also, are there any differences in the results produced by the three techniques? This question has received some previous attention since Baum \& Oler (1968) attempted to compare flooding-1 and flooding-3, while Polin (1959) and Shearman (1970) compared the relative efficacy of flooding-1 and flooding-2. The present experiment sought to compare all three techniques for carrying out flooding, when all three were carried out under comparable conditions for the same duration of time and in the same apparatus.

\section{METHOD \\ Subjects}

The Ss were 75 female hooded rats of Long-Evans origin obtained from the Canadian Breeding Farm, St. Constant, Quebec. The animals were caged singly and maintained on ad lib feeding and drinking schedules prior to the experiment, and weighed $150-250 \mathrm{~g}$.

\section{Apparatus}

The automated, one-way avoidance apparatus used here has been described in full detail elsewhere (Baum, 1966). Briefly, it consisted of a large plywood and Plexiglas box fitted with a grid floor. Scrambled shock could be administered through the grid by means of a Grason-Stadler shock source. The shock level was set at $0.5 \mathrm{~mA}$ at all times. Into one side of the box protruded a $5.5-\mathrm{cm}$ wide retractable ledge onto which the animal could climb to escape or avoid shock. On climbing the ledge, the animal broke a photobeam which thus indicated to the programming equipment the location of the rat. A Plexiglas panel which could be lowered into the avoidance box in such a way as to deny access of the rat to the ledge was used to carry out flooding- 2 . 
Table 1

Summary of the Results of the Experiment*

\begin{tabular}{|c|c|c|c|c|c|c|}
\hline & \multicolumn{5}{|c|}{ Group } & \multirow[b]{2}{*}{ Kruskal-Wallis $\mathbf{H}=$} \\
\hline & F-1 & F-2 & F-3 & TC & $\mathrm{C}$ & \\
\hline $\begin{array}{l}\text { Median number of acquisition trials to learning criterion } \\
\text { Median number of shocks received in acquisition } \\
\text { Median number of responses made in extinction testing }\end{array}$ & $\begin{array}{r}23.0 \\
7.0 \\
0.0\end{array}$ & $\begin{array}{r}25.0 \\
6.0 \\
0.0\end{array}$ & $\begin{array}{r}20.0 \\
7.0 \\
1.0\end{array}$ & $\begin{array}{r}21.0 \\
7.0 \\
10.0\end{array}$ & $\begin{array}{r}27.0 \\
7.0 \\
47.0\end{array}$ & $\begin{array}{l}0.54, \text { n.s. } \\
0.57, \text { n.s. } \\
34.12, \mathrm{p}<.001\end{array}$ \\
\hline $\begin{array}{l}\text { Proportion of animals in each group making } \\
\text { zero responses in extinction }\end{array}$ & $13 / 15$ & $13 / 15$ & $5 / 15$ & $4 / 15$ & $0 / 15$ & \\
\hline $\begin{array}{l}\text { Proportion of animals in each group making } \\
\text { more than five responses in extinction }\end{array}$ & $0 / 15$ & $2 / 15$ & $5 / 15$ & $10 / 15$ & $15 / 15$ & \\
\hline
\end{tabular}

${ }^{*} N=15$ for each group

This panel was placed parallel to and at a level $10 \mathrm{~cm}$ above the grid floor for the group receiving flooding- 2 .

\section{Procedure}

The procedure involved avoidance acquisition and extinction which were the same for all five groups. The groups differed only in the nature of the procedure which was interpolated between acquisition training and extinction testing.

\section{Avoidance Acquisition}

Without prior habituation to the avoidance apparatus, each rat was dropped onto the grid floor via the ceiling door. Ten seconds after the rat had landed on the grid, the grid was electrified and the rat received $0.5 \mathrm{~mA}$ footshock until it escaped by climbing or jumping onto the overhead safety ledge. The rat was allowed to remain on the ledge for $30 \mathrm{sec}$ (the intertrial interval), after which the ledge was automatically retracted for a moment, causing the animal to fall to the grid floor and thus initiating the next training trial. Throughout training, the rat was allowed to avoid receiving shock by jumping or climbing onto the ledge within $10 \mathrm{sec}$ of having been deposited on the grid. Each rat was trained until it reached a learning criterion of 10 consecutive avoidance responses.

\section{Flooding or Control Procedure}

After attaining the acquisition criterion, the shocker was disconnected and the rats were assigned to one of five groups. Group $C(N=15)$, a control group, received no delay between acquisition and extinction and proceeded immediately to Phase 3 of the procedure, extinction testing (see below). Group TC $(n=15)$, a time-control group, was removed from the avoidance apparatus upon the attainment of the acquisition criterion and placed in a nearby plastic pail (a neutral environment) for 9 consecutive min. After the 9 min elapsed, animals in Group TC proceeded to receive avoidance extinction testing. The remaining three groups, each having $n=15$, all received one of the three different flooding procedures in between acquisition and extinction. For rats in Group F-1 (flooding-1), the procedure involved removing the rat from the apparatus upon attainment of the acquisition criterion and placing it in the plastic pail for $2 \mathrm{~min}$. During these $2 \mathrm{~min}$, the apparatus was prepared for flooding. After the 2-min waiting period, the rat was returned to the grid floor of the avoidance apparatus, and now, if it climbed onto the overhead ledge, the ledge was immediately retracted, that is, the intertrial interval had been reduced to zero so that flooding-1 was administered. Physically, the avoidance apparatus had not been altered to administer flooding- 1 . The flooding period remained in effect for 5 consecutive min, at the end of which the rat was returned to the plastic pail for another 2 min waiting period during which the equipment was prepared for extinction testing.

Flooding-2 was administered to Group F-2 also for $5 \mathrm{~min}$ in duration in the following way. After the 2-min waiting period in the pail following avoidance acquisition, the rats in Group F-2 were returned to the grid floor and the Plaxiglas panel was inserted in the apparatus above the rat's head and parallel to the grid floor, thus blocking access to the ledge. After the $5 \mathrm{~min}$ of flooding had elapsed, each rat in Group F-2 was returned to the plastic pail for 2 min while the Plexiglas panel was removed and the apparatus prepared for extinction testing.

Flooding-3 was applied to animals in Group F-3 also for $5 \mathrm{~min}$ and also following a 2-min waiting period in the pail immediately after attainment of the acquisition criterion. For Group F-3, the flooding began by placing the rat on the grid floor while the ledge had been disengaged and completely removed from the apparatus. After the $5 \mathrm{~min}$ of flooding had elapsed, the $S$ was returned to the plastic pail for another 2 min waiting period while the apparatus was prepared for extinction testing.

In summary, all three flooding groups had a 9-min delay between completion of avoidance acquisition and beginning of avoidance extinction. During 5 of these $9 \mathrm{~min}$, each rat was forced to be exposed to the grid floor of the avoidance apparatus, the effective fear CS. The manner in which the forced exposure was accomplished defined the flooding condition (1, 2 , or 3). Group TC animals received no flooding but had the same 9-min time delay following acquisition as did Groups F-1, F-2, and F-3.

\section{Extinction Testing}

After the final minutes in the plastic pail, each rat was returned to the avoidance apparatus and placed on to the safety ledge, thus starting the 30 -sec intertrial interval preceding the first extinction trial. (For animals in Group C, there was no break between acquisition and extinction.) The extinction testing was the same for all groups, with extinction trials being identical to the acquisition trials in every respect, except that the shocker was disconnected so that no shocks could be administered. Extinction proceeded until each rat had attained the extinction criterion of 5 consecutive min on the grid floor without responding (when the response was now possible), or until a maximum of 75 responses had been made.

\section{RESULTS}

The results of the experiment are seen in Table 1. As seen in the table, acquisition of the avoidance response, as measured by either total number of learning trials or number of shocks (escape trials) received, was similar for all five groups. The number of responses made in extinction following the differential flooding or control procedures (administered after acquisition) was significantly different among the five groups.

Table 2 shows the results obtained in comparing 
extinction responses in two groups at a Time by Means of a Mann-Whitney U-test (Siegel, 1956). The most salient features of the results are that Groups F-1 and F-2 do not differ from each other, but both make significantly fewer responses in extinction than Groups F-3, TC, and C. Group C makes significantly more responses than any other group, while the difference between Groups TC and F-3 is not significant.

\section{DISCUSSION}

The results indicate that flooding-1 (making the intertrial interval zero) and flooding-2 (response prevention) are equally effective, supporting the findings of Shearman (1970). Both kinds of flooding are clearly effective in eliminating avoidance behavior. In previous comparisons of these two techniques for administering flooding, the results have been contradictory. Polin (1959) claimed to have demonstrated thesuperiority of flooding-1 over flooding-2, while Berman \& Katzev (1972), in a more carefully controlled study, found flooding- 2 was the more effective of the two. Contradictory results obtained in studying this question are probably due to differences in apparatus and procedural parameters used by different investigators.

Flooding-3 seems to be a procedure intermediate between flooding-1 and flooding-2. It inyolves more response prevention than flooding-1, but also allows more freedom to the animal than flooding-2. The finding that flooding- 3 is the least effective method of carrying out flooding is consistent with a previous study (Baum \& Oler, 1968) which demonstrated a greater efficiency for flooding-1 over flooding-3. Furthermore, in the present study, flooding-3 was not significantly superior to a control time period in a neutral situation (Group F-3 vs Group TC). This lack of significant difference seems peculiar to the particular parameters employed in this study, since the general finding is that flooding- 3 is more effective in eliminating avoidance than is the mere passage of time (e.g., Baum, 1966, 1972).

The inferiority of flooding-3 when compared to the alternative flooding techniques may be attributed to the fact that this is the only technique which permits the animal to engage in "abortive avoidance activity" during flooding. The occurrence of such activity, which consists of rearing and searching for the removed safety ledge, correlates negatively with success of flooding (e.g., Baum, in press). Flooding-1 permits the animal to perform the avoidance response in its entirety and then immediately returns the animal to the feared stimulus, the grid floor. Flooding-2 simply blocks any attempts to rear and search for the ledge. Thus, only flooding-3 permits the animal the freedom to engage in abortive avoidance activity for considerable time periods during flooding, and it is also the least effective technique in this study.

The present study provides a review of the various techniques used to expose an animal to a feared cue in the absence of pain, while removing the avoidance contingency. The comparison of the three flooding techniques in the ledge box is useful, because much previous work on avoidance extinction has been carried out in the author's laboratory using this apparatus and paradigm, usually with flooding-3. Additional research is required comparing the various flooding techniques in a variety of avoidance apparatuses and conditions, to determine the circumstances in which any particular flooding technique will yield the best results in hastening the extinction of avoidance behavior.

\section{REFERENCES}

Bankart, B. An investigation of techniques used to facilitate the extinction of avoidance behavior. Paper presented at the Eastern Psychological Association meeting, New York City, 1971.
Table 2

Summary of the Results Obtained by Comparing Two Groups at a Time on the Number of Responses Made in Extinction Testing

\begin{tabular}{lcl}
$\begin{array}{c}\text { Groups } \\
\text { Compared }\end{array}$ & $\begin{array}{c}\text { Mann-Whitney } \\
\text { U Test }\end{array}$ & $\begin{array}{c}\text { p Value } \\
\text { (Two-Tailed) }\end{array}$ \\
\hline F-3 vs TC & 107.5 & n.s. \\
F-3 vs F-1 & 49.0 & $<.02$ \\
F-3 vs F-2 & 59.5 & $<.05$ \\
F-3 vs C & 36.0 & $<.002$ \\
F-2 vs TC & 55.0 & $<.02$ \\
F-2 vs F-1 & 110.5 & n.s. \\
F-2 vs C & 19.5 & $<.002$ \\
F-1 vs TC & 54.0 & $<.02$ \\
F-1 vs C & 1.0 & $<.002$ \\
TC vs C & 1.5 & $<.002$ \\
\hline
\end{tabular}

Baum, M. Rapid extinction of an avoidance response following a period of response prevention in the avoidance apparatus. Psychological Reports, 1966, 18, 59-64.

Baum, M. Flooding or response prevention or detainment or forced reality-testing: A note on nomenclature. Psychological Reports, 1971, 28, 558 .

Baum, M. Repeated acquisition and extinction of avoidance in rats using flooding (response prevention). Learning \& Motivation, 1972, 3, 272-278.

Baum, M. Extinction of avoidance in rats: The effects of chlorpromazine and methylphenidate administered in conjunction with flooding (response prevention). Behavior Research \& Therapy, in press.

Baum, M., \& Oler, I. D. Comparison of two techniques for hastening extinction of avoidance-responding in rats. Psychological Reports, 1968, 23, 807-813.

Berman, J. S., \& Katzev, R. D. Factors involved in the rapid elimination of avoidance behavior. Behaviour Research \& Therapy, 1972, 10, 247-256.

Bersh, P. J., \& Keltz, J. R. Pavlovian reconditioning and the recovery of avoidance behavior in rats after extinction with response prevention. Journal of Comparative \& Physiological Psychology, 1971, 76, 262-266.

Heath, G. H. A comparison of reciprocal inhibition and flooding in decreasing the strength of a conditioned avoidance response. Paper presented at the Eastern Psychological Association meeting, Washington, D. C., 1968.

Kamano, D. $K$. Joint effect of amobarbital and response prevention on CAR extinction. Psychological Reports, 1968. 22, 544-546.

Linton, J., Riccio, D. C., Rohrbaugh, M., \& Page, H. A. The effects of blocking an instrumental avoidance response: Fear reduction or enhancement? Behaviour Research \& Therapy, $1970,8,267-272$.

Page, H. A., \& Hall, J. F. Experimental extinction as a function of the prevention of a response. Journal of Comparative \& Physiological Psychology, 1953, 46, 33-34.

Polin, A. T. The effects of flooding and physical suppression as extinction techniques on an anxiety motivated avoidance locomotor response. Journal of Psychology, 1959, 47, 235-245.

Reid, L. D., Taylor, C. L., \& Rassel, L. M. Efficient deconditioning of avoidance. Paper presented at the Psychonomic Society meeting, St. Louis, 1971.

Schiff, R. Effect of length and number of blocked trials on extinction of an avoidance response. Paper presented at the Eastern Psychological Association meeting, New York City, 1971.

Shearman, R. W. Response-contingent CS termination in the extinction of avoidance learning. Behaviour Research \& Therapy, 1970, 8, 227-239.

Siegel, $S$. Nonparametic statistics for the behavioral sciences. New York: McGraw-Hill, 1956.

(Received for publication September 21, 1972.) 